\title{
Microstructural Analysis of Silica Fume Concrete with Scanning Electron Microscopy and X-Ray Diffraction
}

\author{
Burhan Uzbas \\ Department of Civil Engineering \\ Faculty of Engineering, Ataturk University \\ Erzurum, Turkey \\ burhanuzbas@gmail.com
}

\author{
Abdulkadir Cuneyt Aydin \\ Department of Civil Engineering \\ Faculty of Engineering, Ataturk University \\ Erzurum, Turkey \\ acaydin@atauni.edu.tr
}

\begin{abstract}
The effects of using different ratios of silica fume on the mechanical and microstructural properties of hardened cement paste and concrete were investigated in this study. Portland cement was replaced with $5 \%, 10 \%, 15 \%$, and $20 \%$ silica fume (SF) by weight. Microstructural properties of obtained samples were investigated by X-Ray Diffraction (XRD) and Scanning Electron Microscopy (SEM). The XRD analysis showed that the ratio of calcium hydroxide $(\mathrm{CH})$, which is produced by hydration, decreases depending on the concrete age and the amount of silica fume. The SEM analysis showed that the use of silica fume decreases gaps and calcium silicate hydrate $(\mathrm{C}$ $\mathrm{S}-\mathrm{H})$ which is also a hydration production. Silica fume content of up to $15 \%$ improved the observed mechanical and microstructural properties of concrete. At the optimum value of $15 \%$, improvement in the paste was observed due to the filler effect and the reaction between the silica fume and calcium hydroxide, leading to a reduction in calcium hydroxide in the concrete.
\end{abstract}

Keywords-silica fume; microstructure of concrete; scanning electron microscopy; $x$-ray diffraction; calcium hydroxide

\section{INTRODUCTION}

Increasingly strong pressure has been placed on natural resources due to the rapid economic development and the growth of the global population. Concrete production is common use of natural resources. Incorporating natural resources in concrete leads to environmental, economic, and technological benefits. One of the most important constituents of concrete is cement, which plays a crucial role as a foundational material in terms of structural costs, however, the use of natural reserves that contain pozzolanic materials rather than cement has become increasingly important [1]. From the economic point of view, cement and fine aggregates contribute the bigger portion of cost in the production of concrete, thus to have them replaced by waste material of similar characteristics has a major economic gain, while being more environmentally friendly [2]. Most of the increase in cement demand will be met by the use of supplementary cementing materials, in order to reduce the green gas emission. Industrial waste, such as blast furnace slag, fly ash, and silica fume are being used as supplementary cement replacement materials and, recently, agricultural waste is also being used as pozzolanic material in concrete [3]. The size of silica fume is hundreds of times smaller than cement particles, causing decrease to the permeability of concrete. Reduction in the permeability of concrete decreases the deterioration caused by several factors such as alkali-aggregate reaction, carbonation, chloride attack, freezing and thawing, sulfate attack, etc. [4].

Silica is a very fine-grained powder obtained by the reduction of high-purity quartzite with coal and wood particles in electric arc furnaces used in the production of silicon metal or ferrosilicon (FeSi) alloys. In the low-temperature upper section of the furnace, $\mathrm{SiO}_{2}$ gas is rapidly oxidized upon contact with the air and condenses as amorphous $\mathrm{SiO}_{2}$ to form silica smoke [5]. Silica fume is a pozzolanic material that is a byproduct of the silicon smelting process. It is known to produce high-strength concrete and is thus typically used either as a direct replacement for a proportion of the cement in concrete (usually for economic reasons) or an additive to improve the properties of concrete in both its fresh and hardened states, including reducing shrinkage and creep, increasing compressive strength, tensile and flexural strength, and optimizing its elastic modulus. Silica fume is used in the production of high-strength concrete, reducing the required amount of cement [6]. Silica fume is typically used at replacement levels of 5\%-10\% in high-performance concrete to improve strength and durability. Silica fume not only reacts with calcium hydroxide $\left(\mathrm{Ca}(\mathrm{OH})_{2}\right)$ to produce calcium silicate hydrate $(\mathrm{CSH})$ but also modifies the microstructure of cement paste due to its fine particle size [7,8].

The replacement of $20 \%$ cement with silica fume and the addition of superplasticizer in the mortar create a thinner interface area compared to plain cement mortar. This is due to the ability of silica fume to act as a filler material and to provide additional hydration, with the cement and silica fume particles mixing to provide microstructure condensation and better packaging. The addition of $20 \%$ silica fume also increases significantly the amount of silicon dioxide $\left(\mathrm{SiO}_{2}\right)$ in the interface zone between the cylindrical aggregate and the mortar matrices [9]. A silica fume admixture provides additional CSH gels such as other pozzolans, and the fine silica 
fume particles fill the aggregate-dough interface area to enhance concrete strength [10]. When added to fresh concrete, the silica fume reacts chemically with $\mathrm{Ca}(\mathrm{OH})_{2}$ to produce additional CSH increasing concrete's compressive strength and chemical resistance. This is because the silica fume fills the cavities in the hydrated cement paste to form a denser structure. The addition of silica smoke increases the cement hydration rate and accelerates $\mathrm{C}_{3} \mathrm{~S}$ and $\mathrm{C}_{3} \mathrm{~A}$ hydration within the first few hours [11]. Microstructural studies have shown that, in mortars containing silica fume, the reduction in the number of gaps causes the reaction of silica fume with $\mathrm{Ca}(\mathrm{OH})_{2}$ around sand particles. The addition of silica fume to concrete increases compressive strength, reduces shrinkage, increases wear resistance, increases adherence, and decreases permeability [12].

Incorporating a silica fume blend as an additive to cement is potentially very useful, as it results in increased strength of concrete. In this study, the specific effects of silica fume on cement hydration are investigated. More specifically, X-Ray Diffraction (XRD) and Scanning Electron Microscopy (SEM) are used to identify the mechanical and physical properties of concrete produced using silica fume. Silica fume is generally added to concrete at a lower rate, but in this study four different rates were used. In addition, the internal structure of concretes containing silica fume have been generally examined with a single device (SEM or XRD). In this study, SEM and XRD were used simultaneously and the internal structure was examined.

\section{MATERIALS AND METHODS}

In this study, cement (CEM I 42.5) from the Votarantim Hasanoglan Cement Factory and silica fume produced as a byproduct of ferrosilicon steel production in Egypt were used. The chemical composition of these materials is shown in Table I. Coarse aggregates with a maximum particle size of $16 \mathrm{~mm}$ were used for the concrete specimens.

TABLE I. CHEMICAL COMPOSITION OF PORTLAND CEMENT AND SILICA FUME TYPE STYLES

\begin{tabular}{|c|c|c|}
\hline \multicolumn{3}{|c|}{ Chemical composition } \\
\hline Oxide & Cement(\%) & Silica fume (\%) \\
\hline $\mathrm{SiO}_{2}$ & 19.43 & 93.65 \\
\hline $\mathrm{Al}_{2} \mathrm{O}_{3}$ & 5.31 & 0.28 \\
\hline $\mathrm{Fe}_{2} \mathrm{O}_{3}$ & 3.79 & 0.58 \\
\hline $\mathrm{CaO}$ & 64.39 & 0.28 \\
\hline $\mathrm{MgO}$ & 2.25 & 0.25 \\
\hline $\mathrm{K}_{2} \mathrm{O}$ & 0.90 & 0.87 \\
\hline $\mathrm{Na}_{2} \mathrm{O}$ & 0.09 & - \\
\hline $\mathrm{SO}_{3}$ & 2.47 & 0.38 \\
\hline Loss on ignition & 1.07 & - \\
\hline
\end{tabular}

$\mathrm{XRD}$ and SEM techniques were used to determine the microstructure of the concrete. Further, a variety of mix proportions to form cement pastes both with and without silica fume were used. Four cement pastes with varying proportions of silica fume based on weight were prepared: $5 \%, 10 \%, 15 \%$, and $20 \%$ (referred to as SF5, SF10, SF15, and SF20, respectively). These were compared to concrete made from a cement-only paste (CS). The concrete was mixed with water to cement/silica fume ratio of 0.60 . A rotary mixer was used to mix the specimens. For the cement pastes, the binders (i.e., CEM I and silica fume) were first blended in the mixer for three minutes before adding water and mixing for another two minutes. The mixes were then poured into oiled molds of size $150 \times 150 \times 150 \mathrm{~mm}^{3}$, compacted, and covered for 24 hours. The specimens were then removed from the molds and cured in water at a constant $20 \pm 2{ }^{\circ} \mathrm{C}$ temperature. Three specimens of each mix were used for compressive strength tests at 7,28, and 90 days after curing. Some of the specimens were selected for microstructure analysis using XRD and SEM. The concrete mix designs are summarized in Table II.

TABLE II. MIX PROPOPRTIONS OF THE CONCRETE SPECIMENS

\begin{tabular}{|c|c|c|c|c|c|c|}
\hline \multicolumn{2}{|c|}{ MIX (1 M3) } & CS & SF5\% & SF10 & SF15 & SF20 \\
\hline \multicolumn{2}{|c|}{$\begin{array}{l}\text { Water to cement } \\
\text { ratio }\end{array}$} & 0.60 & 0.60 & 0.60 & 0.60 & 0.60 \\
\hline \multicolumn{2}{|c|}{ Cement (kg) } & 350.00 & 332.50 & 315.00 & 297.50 & 280.00 \\
\hline \multicolumn{2}{|c|}{ Water $(\mathrm{kg})$} & 210.00 & 210.00 & 210.00 & 210.00 & 210.00 \\
\hline \multirow{4}{*}{$\begin{array}{l}\text { Agg. } \\
(\mathrm{kg})\end{array}$} & $0-2 \mathrm{~mm}$ & 689.00 & 682.00 & 676.00 & 670.00 & 664.00 \\
\hline & $2-4 \mathrm{~mm}$ & 350.00 & 350.00 & 350.00 & 350.00 & 350.00 \\
\hline & $4-8 \mathrm{~mm}$ & 280.00 & 280.00 & 280.00 & 280.00 & 280.00 \\
\hline & $8-16 \mathrm{~mm}$ & 420.00 & 420.00 & 420.00 & 420.00 & 420.00 \\
\hline \multicolumn{2}{|c|}{ Silica fume $(\mathrm{kg})$} & 0.00 & 17.50 & 35.00 & 52.50 & 70.00 \\
\hline
\end{tabular}

\section{RESULTS AND DISCUSSIONS}

\section{A. Compressive Strength}

Table III presents the compressive strength of the mixes in comparison to the control mix. It can be observed that, after 7 days of curing, the compressive strength of concrete with silica fume was stronger than that of the control concrete and that the compressive strength increased as the rate of silica fume increased up until SF15, which had the highest compressive strength. However, when the silica fume content was $20 \%$, the compressive strength fell moderately. For all mixtures, the compressive strength increased with curing time, with the comparative strengths between the mixtures exhibiting the same trend after both 28 and 90 days of curing as for 7 days (i.e., CS had the lowest compressive strength and SF15 the highest).

TABLE III. COMPRESSIVE STRENGTH RESULTS

\begin{tabular}{|c|c|c|c|}
\hline \multirow{2}{*}{ Mixes } & \multicolumn{3}{|c|}{ Compressive strength (MPa) } \\
\cline { 2 - 4 } & 7 days & 28 days & 90 days \\
\hline CS & 32.49 & 38.34 & 40.28 \\
\hline SF5 & 32.52 & 41.71 & 42.43 \\
\hline SF10 & 33.62 & 42.10 & 43.28 \\
\hline SF15 & 34.42 & 43.13 & 44.59 \\
\hline SF20 & 33.70 & 41.41 & 43.37 \\
\hline
\end{tabular}

This increase in compressive strength with increasing silica fume content up until $15 \%$ is because the particle size of the silica fume is smaller than that of cement, leading to an increase in the pozzolanic reaction between the $\mathrm{SiO}_{2}$ in the silica fume and the $\mathrm{Ca}(\mathrm{OH})_{2}$ from the hydration process.

\section{B. SEM and XRD Analysis}

When cement paste is viewed at higher magnifications, the hydration products and particles of unhydrated cement are visible. XRD microanalysis allows quantitative chemical composition analysis. In addition, SEM allows the cement and 
concrete microstructure to be characterized [13]. SEM is a commonly used analytical technique due to the ease of sample preparation, the diversity of information it can collect, its high resolution associated with a high-field depth, and its broad, continuous range of magnification [14]. The XRD patterns of the hydration products and SEM images were analyzed for the control mix and the four silica fume specimens. The results are presented in Figures 1-15. The presence of $\mathrm{Ca}(\mathrm{OH})_{2}$ was attributed to the partial carbonation of portlandite. After 28 days of curing, the intensity of the main ettringite peaks reduced significantly in the $\mathrm{CS}$. This can be explained by the transformation of calcium sulphoaluminate into a more stable form of calcium aluminate hydrate.

Figure 1 presents the XRD and SEM results of the control mix (CS) after 7 days of curing. The young concrete had strong peaks due to calcium and silicon and weak peaks from impurities of aluminum and iron. In the SEM image, hexagonal calcium hydroxide $(\mathrm{CH})$, needle-like ettringite, and sheet-like $\mathrm{CSH}$ can be observed. Figures 2 and 3 present the XRD and SEM results of SF5 and SF10 respectively after 7 days of curing. Strong peaks were observed for calcium and silicon, but there was a considerable lower amount of calcium hydroxide compared to CS.
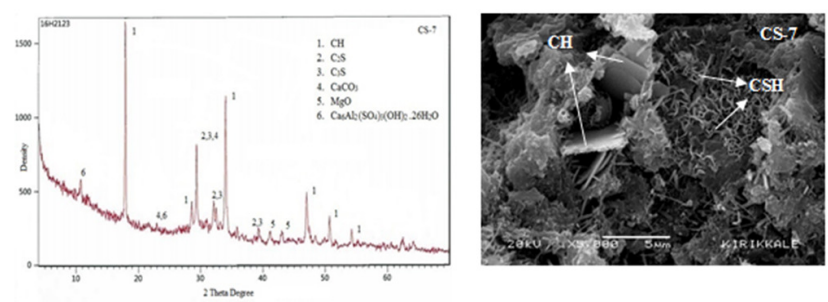

Fig. 1. XRD and SEM analysis of the control mix (CS) after 7 days
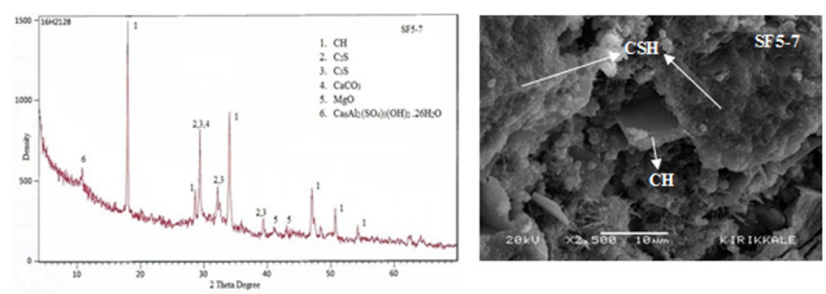

Fig. 2. XRD and SEM analysis of SF5 mix after 7 days
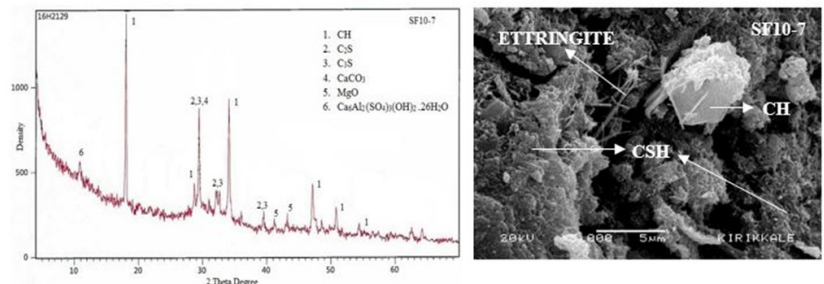

Fig. 3. XRD and SEM analysis of SF10 mix after 7 days

Figure 4 presents the XRD and SEM results of SF15 after 7 days of curing. Strong peaks were observed due to calcium and silicon, but there was a significantly lower amount of calcium hydroxide rather than other SF. It can also be seen that the voids in the concrete microstructure were filled to a large extent by the addition of silica fume. Figure 5 presents the XRD and SEM results of SF20 after 7 days of curing. Strong peaks were observed due to calcium and silicon, but, as with SF15, there was a considerable decrease in calcium hydroxide. The SEM image shows the presence of hydrated phases such as $\mathrm{CSH}$ and ettringite.
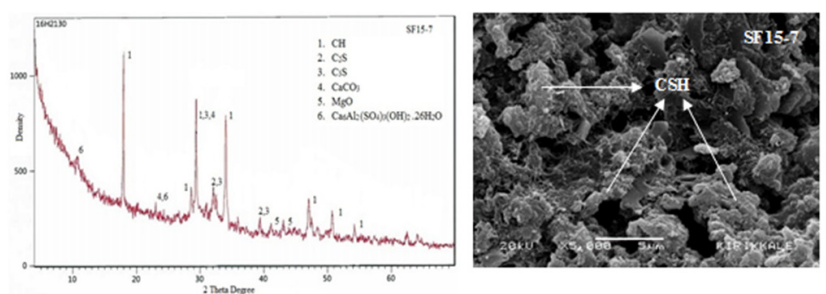

Fig. 4. XRD and SEM analysis of SF15 mix after 7 days
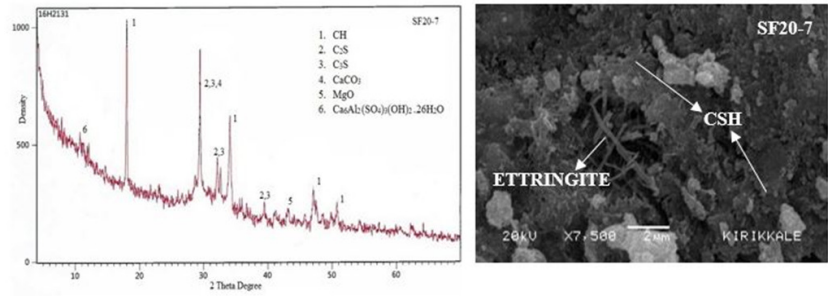

Fig. 5. XRD and SEM analysis of the SF20 mix after 7 days

Figure 6 presents the XRD and SEM results of CS after 28 days of curing. Strong peaks were again observed due to calcium and silicon. Hexagonal calcium hydroxide, needle-like ettringite, and sheet-like CSH can be observed in the SEM image. Figures 7-8 present the XRD and SEM results of SF5 and SF10 respectively after 28 days of curing. Similar to the results after 7 days, strong peaks were observed due to calcium and silicon, but there was a considerably lower amount of calcium hydroxide compared to the $\mathrm{CS}$.
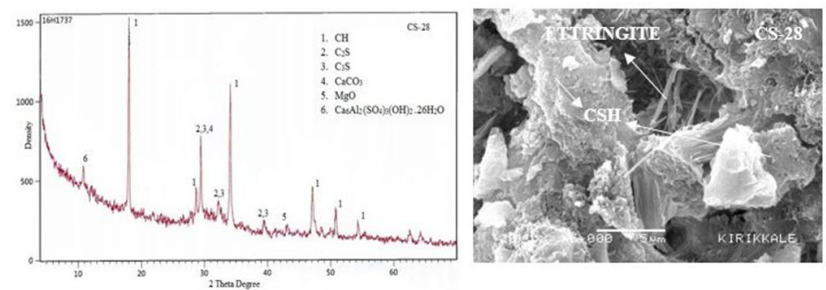

Fig. 6. XRD and SEM analysis of the control mix (CS) after 28 days
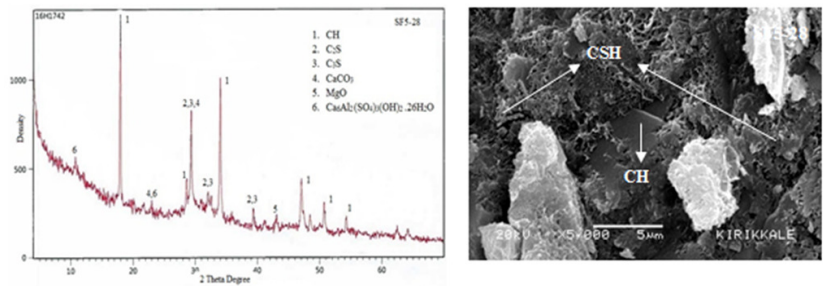

Fig. 7. XRD and SEM analysis of the SF5 mix after 28 days 

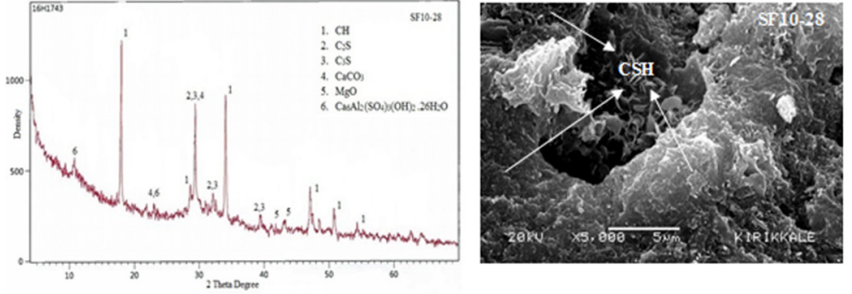

Fig. 8. XRD and SEM analysis of the SF10 mix after 28 days

Figure 9 presents the XRD and SEM results of SF15 after 28 days of curing. Strong peaks are visible due to calcium and silicon, and the SEM image indicates an increasing amount of $\mathrm{C}_{2} \mathrm{~S}$ and $\mathrm{C}_{3} \mathrm{~S}$. Figure 10 presents the XRD and SEM results of SF20 after 28 days of curing. Strong peaks due to calcium and silicon were also observed, while $\mathrm{CH}$ exhibited its lowest value and $\mathrm{C}_{2} \mathrm{~S}$ and $\mathrm{C}_{3} \mathrm{~S}$ their highest.
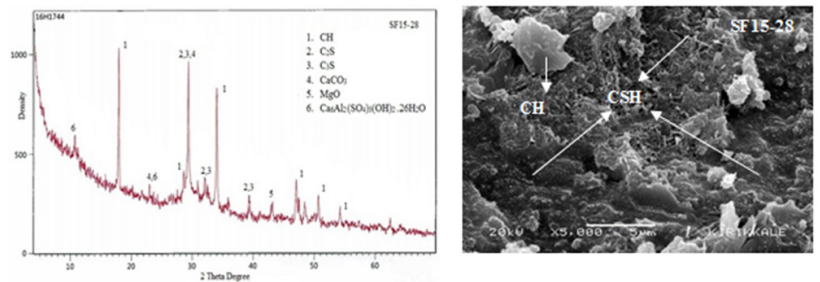

Fig. 9. XRD and SEM analysis of the SF 15 mix after 28 days
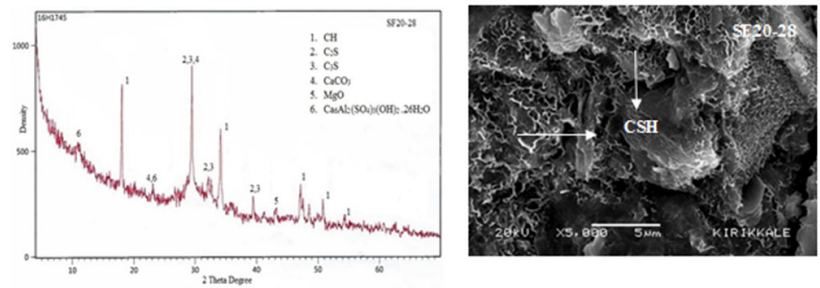

Fig. 10. XRD and SEM analysis of the SF20 mix after 28 days

Figure 11 presents the XRD and SEM results of CS after 90 days of curing. Only CSH can be observed in the SEM image.
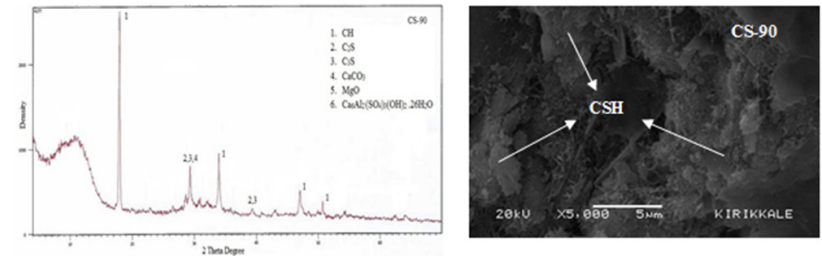

Fig. 11. XRD and SEM analysis of the control mix (CS) after 90 days
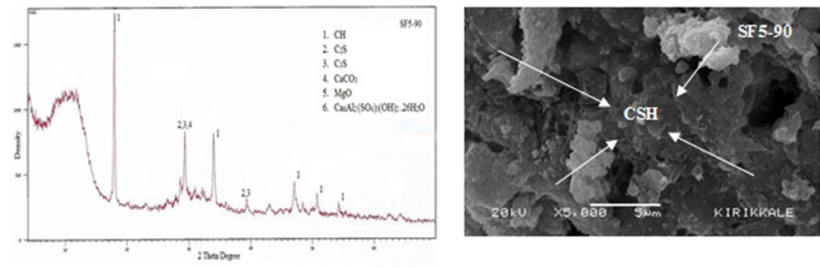

Fig. 12. XRD and SEM analysis of the SF5 mix after 90 days
Figure 12 presents the XRD and SEM results of SF5 after 90 days of curing. Only CSH can be observed in the SEM image. There was a considerable decrease in the amount of calcium hydroxide rather than other SF. It can also be seen that the voids in the microstructure are filled by the addition of silica fume. Figure 13 presents the XRD and SEM results of SF10 after 90 days of curing. Only CSH can be observed. Figure 14 presents the XRD and SEM results for SF15 after 90 days of curing. A considerable decrease in the amount of calcium hydroxide can be seen. $\mathrm{CH}$ reached its lowest value and $\mathrm{C}_{2} \mathrm{~S}$ and $\mathrm{C}_{3} \mathrm{~S}$ their highest. Figure 15 presents the XRD and SEM results of SF20 after 90 days of curing. Only CSH can be observed in the SEM image and the voids in the microstructure are filled to a large extent by the addition of silica fume. $\mathrm{CH}$ reached its lowest value and $\mathrm{C}_{2} \mathrm{~S}$ and $\mathrm{C}_{3} \mathrm{~S}$ their highest.
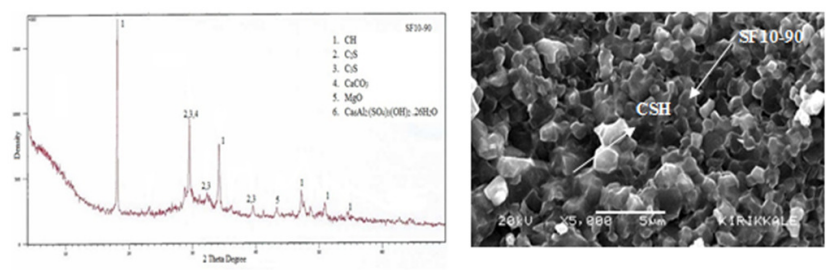

Fig. 13. XRD and SEM analysis of the SF 10 mix after 90 days
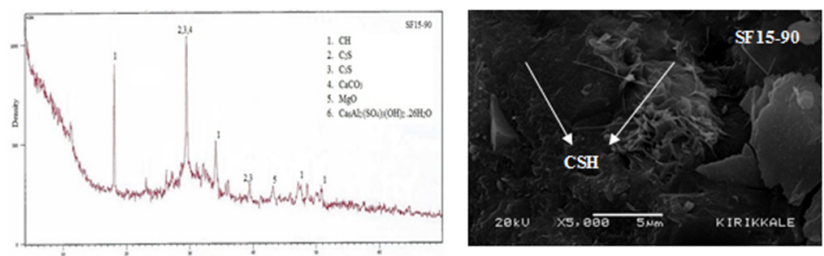

Fig. 14. XRD and SEM analysis of the SF 15 mix after 90 days
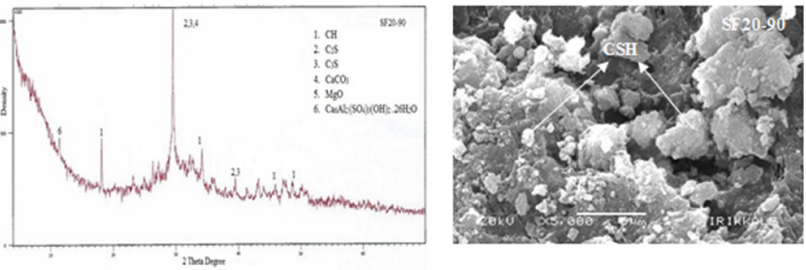

Fig. 15. XRD and SEM analysis of the SF20 mix after 90 days

A considerable increase in the amount of calcium hydroxide $(\mathrm{CH})$ was also observed, primarily due to the increase in the formation of CSH. For all concrete mixes, including CS, it was observed that, after 28 days of curing, the amount of crystalline $\mathrm{CH}$ was reduced compared to the 7-day samples, which is indicated by the shorter length of the $\mathrm{CH}$ peaks. These results are evidence of the reaction of silica fume with $\mathrm{CH}$ to form $\mathrm{CSH}$ matrices. During the hydration of the cement mortars, $\mathrm{CH}$ formation fell with the addition of silica fume, therefore lower compressive strength was attained in the early stages compared to CS. Over time, silica fume, with its pozzolanic structure, bound to $\mathrm{CH}$, producing pozzolanic $\mathrm{CSH}$ gel, and raising the strength of the concrete to reach that of CS. Highly crystalline portlandite and amorphous $\mathrm{CSH}$ are formed during the hydration of Portland cement [15]. $\mathrm{CH}$, which 
occurs as a result of chemical reactions, is soluble in water and has low strength. These properties affect negatively the quality of concrete. Adding a mineral admixture to cement decreases the amount of $\mathrm{Ca}(\mathrm{OH})_{2}$. Cement paste containing silica fume produces amorphous $\mathrm{CSH}$ gel with high density and a low $\mathrm{Ca} / \mathrm{Si}$ ratio. During the chemical reaction period of Portland cement, silicate reacts with free $\mathrm{Ca}(\mathrm{OH})_{2}$, thus forming amorphous $\mathrm{CSH}$ gel. Therefore, the amount of $\mathrm{Ca}(\mathrm{OH})_{2}$, which is harmful for concrete in terms of structural strength, decreases accordingly [15-18]. In examined concrete containing silica fume, all the peaks characterizing the portlandite phase disappear completely. $\mathrm{CH}$ released during cement hydration, was consumed as a result of interaction with active silica fume to form CSH phases [19].

In the present study, an increase in the cement reaction after 7 days was observed due to the small size and high surface area of the silica fume, which increased $\mathrm{CSH}$ nucleation. As the curing time increased, there was a diminution of values between the tobermorite and portlandite phases. This occurred between 7 and 28 days and between 28 and 90 days. This phenomenon can be explained by the fact that during the first 7 days of hydration, tobermorites originating in the alite are more predominant, and alite is present in larger amounts than belite, which is a source of portlandite that develops more slowly. As time passes, a larger amount of portlandite is produced, so that, after 7 days, the difference between tobermorite and portlandite narrows. After 28 days, the difference between the two compounds widened as the development of tobermorite increased substantially. While hydration continued, ettringite became more and more evident throughout [14]. The presence of the portlandite peaks seen in both the XRD and SEM analysis of hardened samples after varying periods of hydration indicated the presence of silica fume. Portlandite, which is formed by the hydration of $\mathrm{C}_{3} \mathrm{~S}$ and $\mathrm{C}_{2} \mathrm{~S}$, combines with silica fume to form $\mathrm{CSH}$. The lack of portlandite peaks in the XRD results can be explained by the poor crystallization of portlandite [16]. Adding silica fume to ordinary concrete leads to the reduction in the $\mathrm{Ca}(\mathrm{OH})_{2}$ produced during cement hydration, because it reacts with the active silica fume to form $\mathrm{CSH}$ [17]. Silica reacts with $\mathrm{CH}$ to produce $\mathrm{CSH}$ due to the acceleration of hydration of tricalcium and diacalcium, which makes the concrete denser and homogeneous [20]. SEM analysis is characterized by easy sampling, variety of accessible knowledge, and good resolution. The XRD method can be used to determine the crystal structure of samples, to conduct quantitative and qualitative phase analysis, to investigate phase transformation, to study crystallographic configuration, and to study the size of crystals [21].

\section{CONCLUSIONS}

In this paper, the effect of silica fume on the microstructure and mechanical properties of concrete was investigated. In addition, the effect of silica fume on the amount of $\mathrm{CH}$ and $\mathrm{CSH}$ in concrete was studied. Silica fume has been shown to improve the microstructure of cement paste in concrete by densifying the cement paste matrix and the porous paste aggregate interfacial zone. In this study, it was observed that the porosity of silica fume concrete decreased as the silica fume content increased up to $15 \%$, after which the porosity increased as the silica fume content increased. Silica fume reduced the amount of $\mathrm{CH}$ for all content levels after 7, 28, and 90 days. A linear relationship between the use of silica as a binder instead of cement and the decrease in $\mathrm{CH}$ was observed. After 7 days of curing, $\mathrm{CH}$ reduced to $10 \%, 13 \%, 31 \%$, and $37 \%$ for silica fume levels of $5 \%, 10 \%, 15 \%$, and $20 \%$, respectively. After 28 days of curing, $\mathrm{CH}$ fell to $11 \%, 20 \%, 32 \%$, and $46 \%$ and after 90 days of curing $\mathrm{CH}$ dropped to $33 \%, 34 \%, 65 \%$, and $81 \%$ for the same silica fume levels respectively. Silica fume also decreased the amount of $\mathrm{CSH}$ at all content levels. After 7 days of curing, $\mathrm{CSH}$ fell to $1 \%, 7 \%, 9 \%$, and $12 \%$, after 28 it fell to $1 \%, 7 \%, 18 \%$, and $19 \%$, and after 90 days to $2 \%, 18 \%, 28 \%$, and $28 \%$ for silica fume levels of $5 \%, 10 \%, 15 \%$, and $20 \%$ respectively.

\section{REFERENCES}

[1] A. C. Aydın, R. Gul, "Influence of volcanic originated natural materials as additives on the setting time and some mechanical properties of concrete", Construction and Building Materials, Vol. 21, No. 6, pp. 1277-1281, 2007

[2] A. A. Adekunle, K. R. Abimbola, A. O. Familusi, "Utilization of construction waste tiles as a replacement for fine aggregates in concrete", Engineering, Technology and Applied Science Research, Vol. 7, No. 5, pp. 1930-1933, 2017

[3] F. A. Olutoge, H. A. Quadri, O. S. Olafusi, "Investigation of the strength properties of palm kernel shell ash concrete", Engineering, Technology and Applied Science Research, Vol. 2, No. 6, pp. 315-319, 2012

[4] A. G. Khan, B. Khan, "Effect of partial replacement of cement by mixture of glass powder and silica fume upon concrete strength", International Journal of Engineering Works, Vol. 4, No.7, pp. 124-135, 2017

[5] A. Yeginobali, "Silica fume and cement and its use in concrete", Turkish Cement Manufacturers' Association, 2009 (in Turkish)

[6] T. Nochaiya, W. Wongkeo, A. Chaipanich, "Utilization of fly ash with silica fume and properties of portland cement-fly ash-silica fume concrete”, Fuel, Vol. 89, No. 3, pp. 768-774, 2010

[7] A. C. A. Muller, K. L. Scrinever, J. Skibsted, A. M. Gajewicz, P. J. McDonald, "Influence of silica fume on the microstructure of cement paste: New insights from H NMR relaxometry", Cement and Concrete Research, Vol. 74, pp. 116-125, 2015

[8] M. Kurt, M. S. Gul, R. Gul, A. C. Aydın, T. Kotan, "The effect of pumice powder self-compactability of pumice aggregate lightweight concrete", Construction and Building Materials, Vol. 103, pp. 36-46, 2016

[9] N. Ranjbar, M. Mehrali, A. Behnia, U. J. Alengaram, M. Z. Jumaat, "Compressive strength and microstructural analysis of fly ash/palm oil fuel ash based geopolymer mortar", Materials and Design, Vol. 59, pp. 532-539, 2014

[10] I. Demir, "Aynı oranda ikame edilen silis dumani ve ucucu kulun betonun mekanik ozelliklerine etkisi", International Journal of Engineering Research and Development, Vol. 1, No. 2, pp. 1-7, 2009 (in Turkish)

[11] K. Baltakys, R. Jauberthie, R. Siaucinas, R. Kaminskas, "Influence of modification of $\mathrm{SiO} 2$ and the formation of calcium silicate hydrate", Materials Science-Poland, Vol. 25, No. 3, pp. 663-670, 2007

[12] I. B. Topcu, M. Canbaz, "An investigation of the interfaces of silica fume concrete", ECAS2002 International Symposium on Structural and Earthquake Engineering, Ankara, Turkey, October 14, 2002

[13] P. E. Stutzman, "Scanning electron microscopy in concrete petrography", Calcium Hydroxide in Concrete (Workshop on the Role of Calcium Hydroxide in Concrete), Anna Maria Island, Florida, USA, November 1-3, 2000

[14] J. Elena, M. D. Lucia, "Application of x-ray diffraction (XRD) and scanning electron microscopy (SEM) methods to the Portland cement hydration processes", Journal of Applied Engineering Sciences, Vol. 2, No. 15 , pp. $35-42,2012$ 
[15] E. Temiz, A. Y. Karakeci, "An investigating on microstructure of cement paste containing fly ash and silica fume", Cement and Concrete Research, Vol. 32, No. 7, pp. 1131-1132, 2002

[16] I. B, Topcu, M. Canbaz, "An investigation of the interfaces of silica fume concrete", International Symposium on Structural and Earthquake Engineering, Ankara, Turkiye, 2002

[17] M. Saad, S. A. A. E. Enein, G. B. Hanna, M. F. Kotkata, "Effect of silica fume on the phase composition and microstructure of thermally treated concrete", Cement and Concrete Research, Vol. 26, No. 10, pp. 14791484, 1996

[18] A. C. Aydin, M. B. Karakoc, O. A. Duzgun, M. S. Bayraktutan, "Effect of low quality aggregates on the mechanical properties of lightweight concrete", Scientific Research and Essays, Vol. 5, No. 10, pp. 11331140, 2010

[19] B. Uzbas, A. C. Aydin, "XRD analysis of mechanical properties of containing fly ash and silica fume concrete", Sinop University Journal of Natural Science, Vol. 3, No. 2, pp. 1-22, 2018

[20] A. K. Nanda, P. P. Bansal, M. Kumar, "Effect of nano silica and silica fume on durability properties of high performance concrete", International Journal of Civil Engineering and Technology, Vol. 9, No. 2, pp. 115-129, 2018

[21] B. Uzbas, A. C. Aydin, "Analysis of fly ash concrete with scanning electron microscopy and x-ray diffraction", Advances in Science and Technology Research Journal, Vol. 13, No. 4, pp. 100-110, 2019 